\title{
Study on the ultimate strength of river-to-sea transport container ship
}

\author{
Diyi Chen ${ }^{1, a}$, Wei Wang ${ }^{2, b}$, Hao Zhang ${ }^{3, c}$ \\ ${ }^{123}$ School of Naval Architecture and Ocean Engineering; Zhejiang Ocean University; Zhejiang \\ Zhoushan 316022; China; \\ adiyi178@163.com, b147298485@qq.com, '906228547@qq.com
}

\begin{abstract}
Key words: river-to-sea transport container ship; ultimate strength; nonlinear finite element method; numerical simulation

Abstract. In this paper, the study takes 521TEU Open Container Ship for example to research ultimate strength of river-to-sea transport container ship, and uses MSC / PATRAN and ABAQUS finite element software to simulate the container ship, and then gets the ship's structure ultimate strength. Further study on how should we to improve the accuracy of numerical simulation and increase the ultimate strength of the hull structure. Finally the paper establishes a reasonable calculation method of ultimate strength, and then gets some valuable conclusions.
\end{abstract}

\section{Introduction}

River-to-sea transport ship has played an important role in the transportation of commodity goods along the river-to-sea city. At the same time, river-to-sea transport container ship will play a major role in it. In today's waste and depletion of resources, harsh environment restricts economic development. So, the development of river-to-sea transport container ship is the objective requirements of coastal area economy and freight volume. Because river-to-sea transport container ship can reduce damage of cargo, turnaround time of cargo, the limits of wharf and storage yard and so on ${ }^{[1]}$. Therefore, in order to improve the transportation volume and the economic security performance of container ship, we must study the ultimate strength of the ship. Hull ultimate strength is an important indicator to measure the maximum carrying capacity of river-to-sea transport container ship ${ }^{[2]}$. Compared to the traditional concept, as long as the actual stress meets the specifications of allowable stress, the ship's structure will be safe. When the actual stress exceeds allowable stress in usually ship structure, the structure will produce plastic deformation and reach the actual use of the limit state.

However, this can only cause local structural failure, and cannot achieve completely damage state. So this is not really the ultimate state of the hull. Therefore, based on the ultimate strength design can better reflect the maximum carrying capacity of resistance external load than the traditional design ${ }^{[2,}$ ${ }^{9}$. Ultimate strength corresponding the ultimate bending moment is hull structural ultimate bearing state on withstanding the maximum bending. Therefore, this paper based on the ultimate bending moment to measure the ultimate strength of ship hull ${ }^{[3,7]}$.

\section{Numerical simulation of ultimate strength of nonlinear finite element method}

Main idea of the method is to use the finite element calculation software MSC/PATRAN to do numerical modeling of river-to-sea transport 521teu container ship, and then importing the model into large finite element software ABAQUS to calculate the ultimate bending moment of container, by the ultimate bending moment to measure the ultimate strength of the ship.

\section{River-to-sea transport 521teu container ship numerical modeling}

This 521teu container ship is a steel, single deck, double hull, double engines and propellers, diesel-powered aft-engine. It can be loaded with $52120 \mathrm{ft}$ containers. According to the 521 teu container ship`s general arrangement plan, general structure plan, typical cross-sectional plan and the transverse bulkhead plan, the range of model is built with full width and $0.5+1+0.5$ length of cargo 
hold in the cargo hold area. Each hull structure is simulated by a plate or beam element ${ }^{[4,5]}$. The model of river-to-sea transport container ship is shown in Fig. 1.

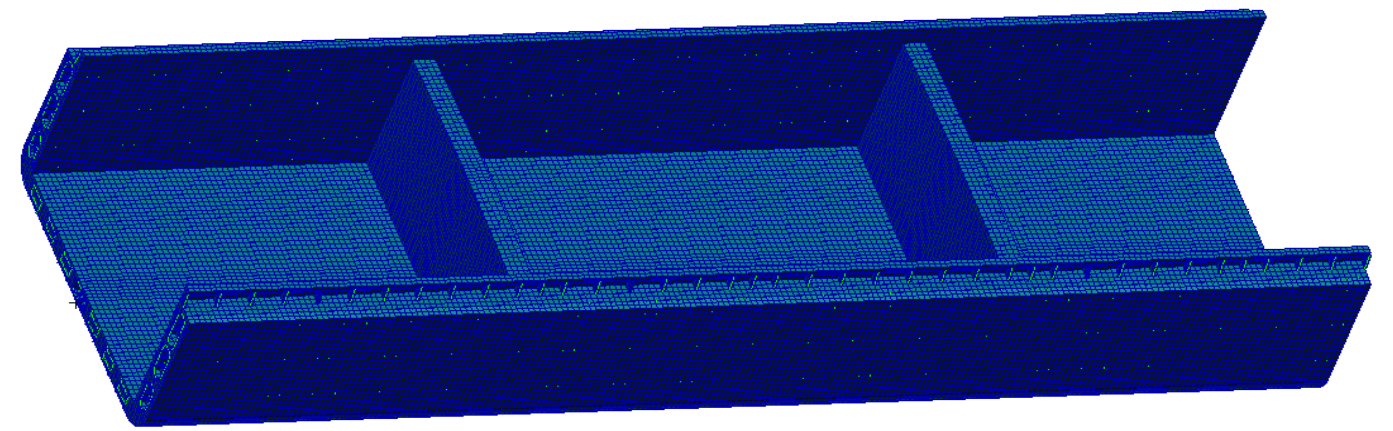

Fig. 1 River-to-sea transport 521teu container ship`s calculation region model

We should pay attention to the division of plate element and beam element ${ }^{[7]}$, and the definition of thickness property, and quadrilateral element aspect ratio of not more than 3 , and triangle element controlled in the between 30 to 150 degrees ${ }^{[5]}$.

\section{River-to-sea transport 521teu container ship ultimate strength numerical calculation}

The model which is built by the finite element software of MSC / PATRAN import into the software of ABAQUS ${ }^{[1]}$, and use the displacement method to calculate the ultimate bending moment ${ }^{[4]}$. The calculation results are shown in Fig. 2 and Fig. 3.

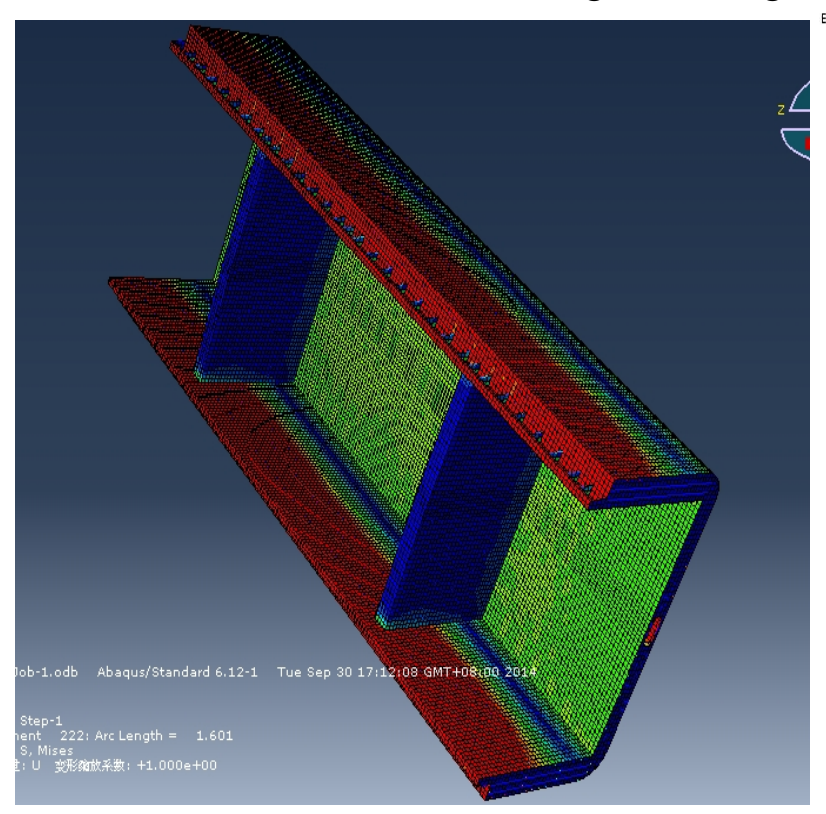

Fig. 2 stress distribution of ultimate failure

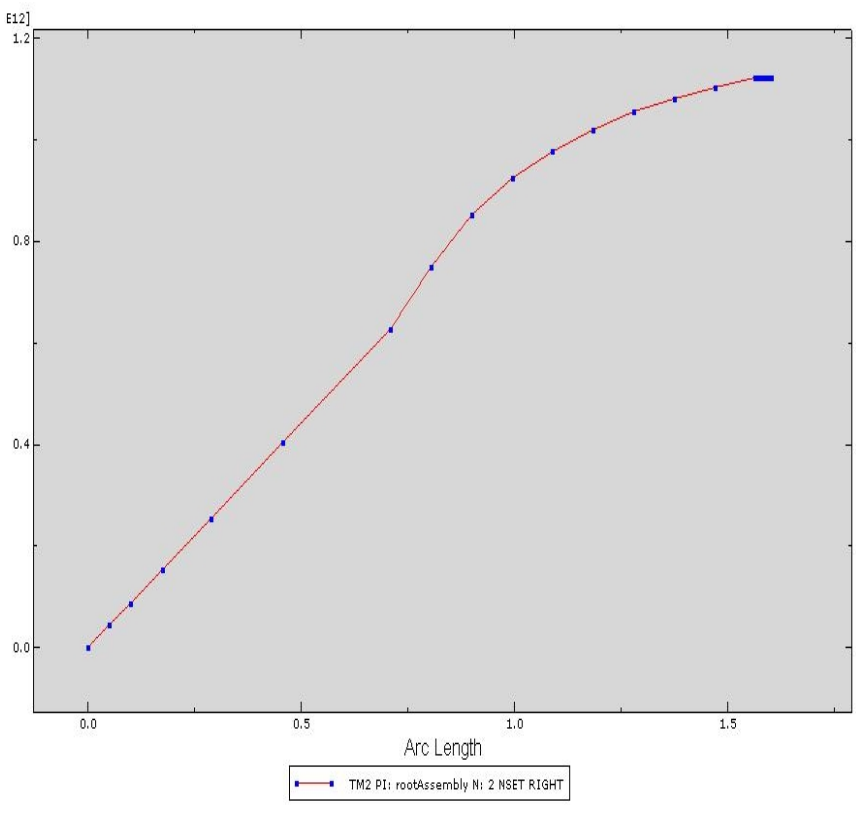

Fig. 3 ultimate bending moment - arc length

The ultimate bending moment of the ship is $1122830 \mathrm{KN} \cdot \mathrm{m}$ by calculating. So, we can use the result to measure the maximum carrying capacity of river-to-sea transport 521teu container ship and to provide further data reference for the hull design.

Factors affecting the value of the ultimate strength of river-to-sea transport 521teu container ship

By numerical simulation, finding some factors has a certain effect on the numerical value of the ultimate bending moment. They are the calculation method of load and displacement, the length of cabin, initial arc length of step size, mesh size, material yield strength and so on ${ }^{[6]}$. Next, the paper focuses on the change of these factors leading to the influence of ultimate bending moment value.

Compare the displacement control and load control two different loading ways making an impact on results of ultimate strength

In order to reduce the time of the numerical simulation, the study choose the size of 0.4 length cabins to compare the impact of displacement control and load control different loading ways on the result 
of ultimate strength. The specific way of loading is shown in tab. ${ }^{[1]}$. The calculations of ultimate bending moment value are shown in Fig. 4 to Fig. 7.

Tab. 1 The boundary condition in different loading methods

\begin{tabular}{|l|l|l|l|l|l|l|}
\hline \multirow{2}{*}{$\begin{array}{l}\text { Loading } \\
\text { method }\end{array}$} & \multicolumn{3}{|l|}{ Linear displacement constraints } & \multicolumn{3}{l|}{ Angular displacement constraints } \\
\cline { 2 - 7 } & $\delta_{\mathrm{X}}$ & $\delta_{\mathrm{Y}}$ & $\delta_{\mathrm{Z}}$ & $\theta_{\mathrm{X}}$ & $\theta_{\mathrm{Y}}$ & $\theta_{\mathrm{Z}}$ \\
\hline \multirow{2}{*}{$\begin{array}{l}\text { displacement } \\
\text { control }\end{array}$} & Cons & Cons & Cons & Cons & & Cons \\
\cline { 2 - 7 } & & Cons & Cons & Cons & & Cons \\
\hline \multirow{2}{*}{ load control } & Cons & Cons & Cons & Cons & Cons & Cons \\
\cline { 2 - 7 } & & Cons & & Cons & $0.01 \mathrm{rad}$ & Cons \\
\hline
\end{tabular}

Cons_-indicates the constraint between relative displacements.

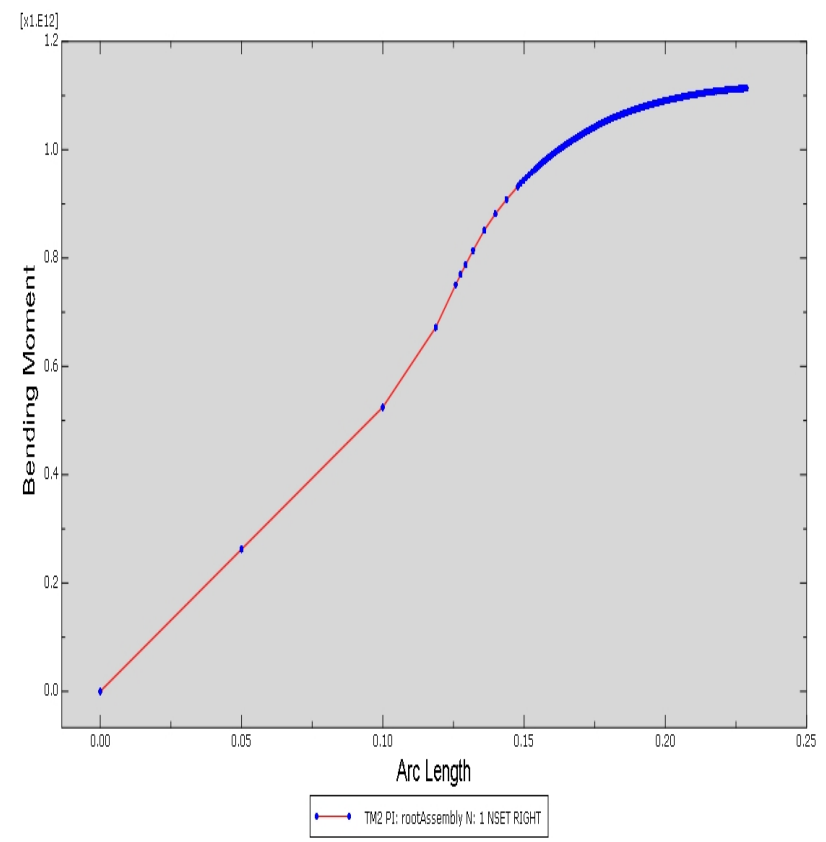

Fig. 4 ultimate bending moment - arc length under the method of displacement control

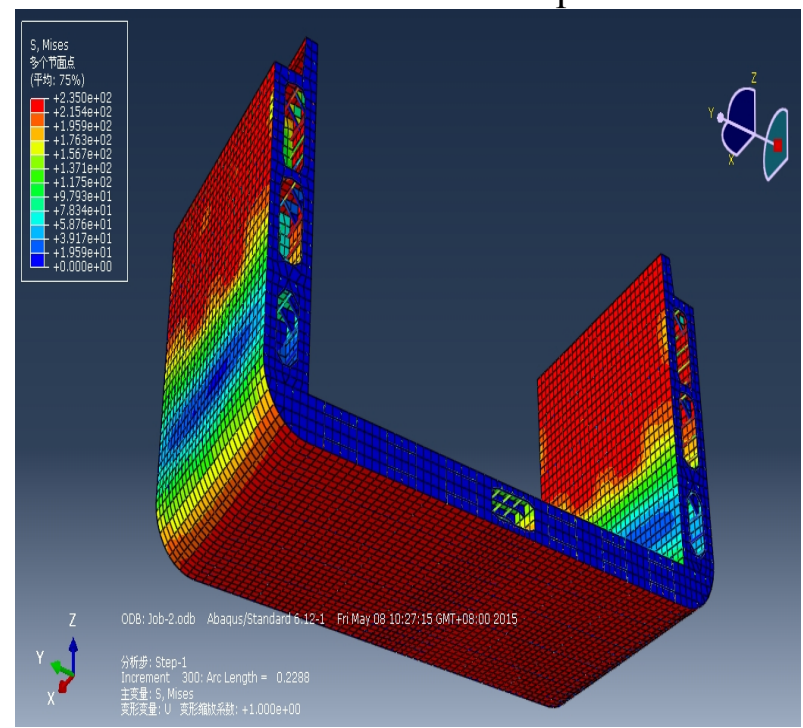

Fig. 6 stress distribution of ultimate failure under the method of displacement control

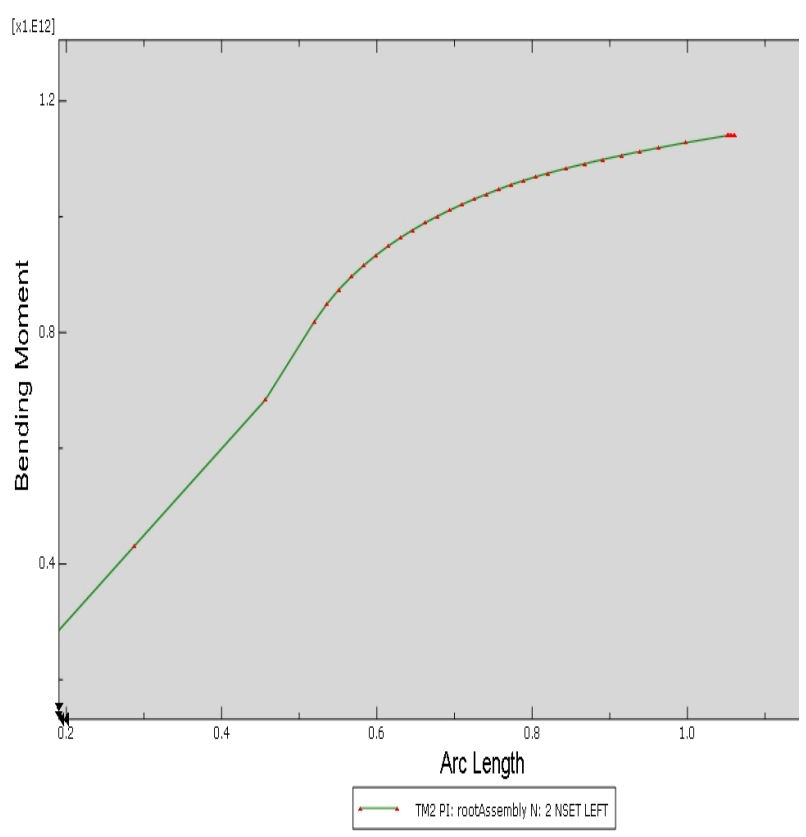

Fig. 5 ultimate bending moment - arc length under the method of load control

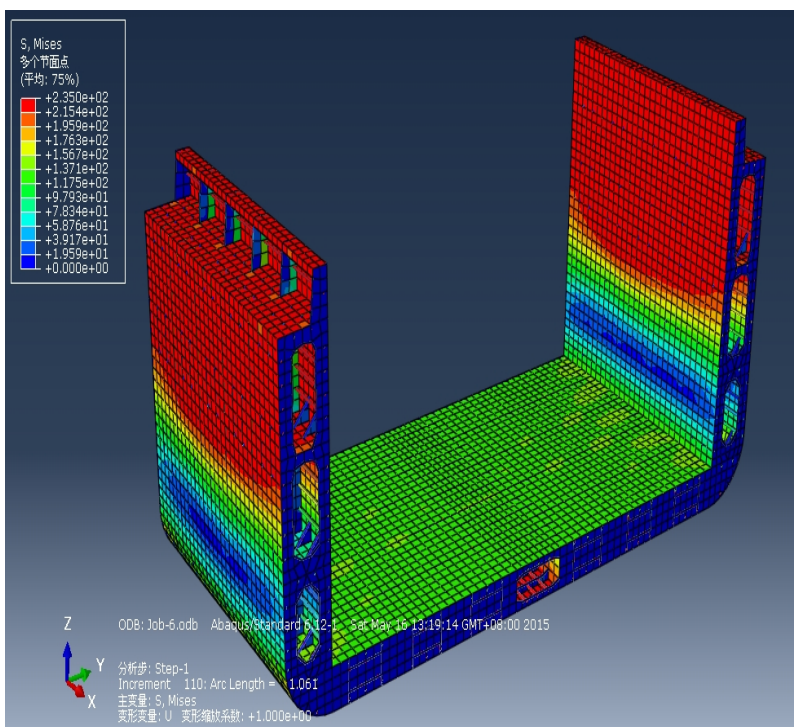

Fig. 7 stress distribution of ultimate failure under the method of load control 
By displacement method calculating, the size of 0.4 cabin's ultimate bending moment is $1113610 \mathrm{KN} \cdot \mathrm{m}$. By load method calculating, the size of 0.4 cabin`s ultimate bending moment is $1140340 \mathrm{KN} \cdot \mathrm{m}$. Obviously the results of the two methods have certain differences. By reference to the papers, displacement method is more close to the real ultimate bending moment ${ }^{[8]}$. Therefore, this paper suggests by the displacement method to calculate the ultimate bending moment.

\section{The influence of different length of cabin on the ultimate strength}

Using the displacement loading method has already calculated the result of ultimate bending moment of the length of 2 cabins and 0.4 cabins. Now using the same method calculates the ultimate bending moment of 0.6 length cabins. By numerical simulation, its result is $1093960 \mathrm{KN} \cdot \mathrm{m}$. The calculation of ultimate bending moment is shown in Fig. 8 and Fig. 9.

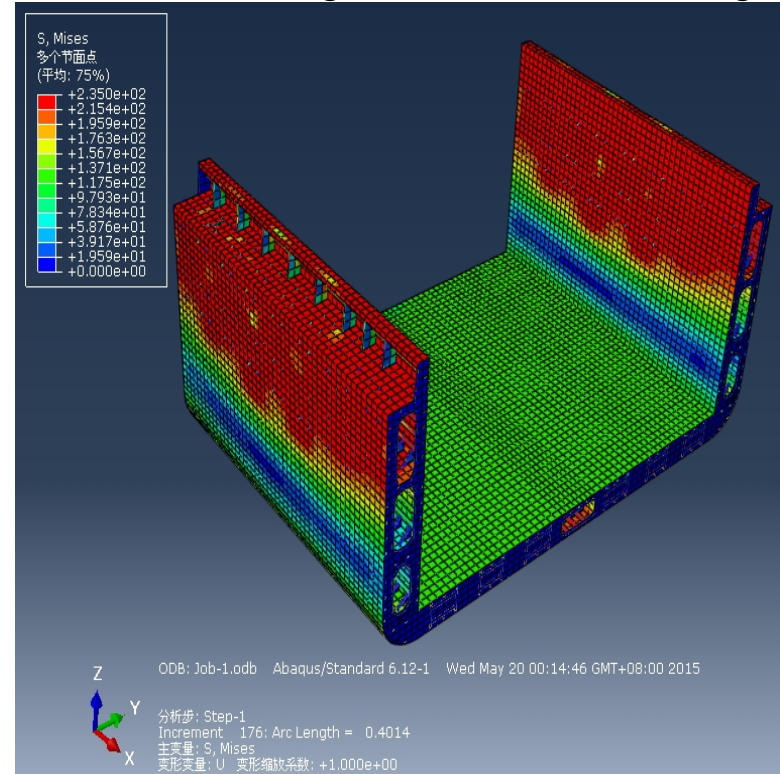

Fig. 8 stress distribution of ultimate failure

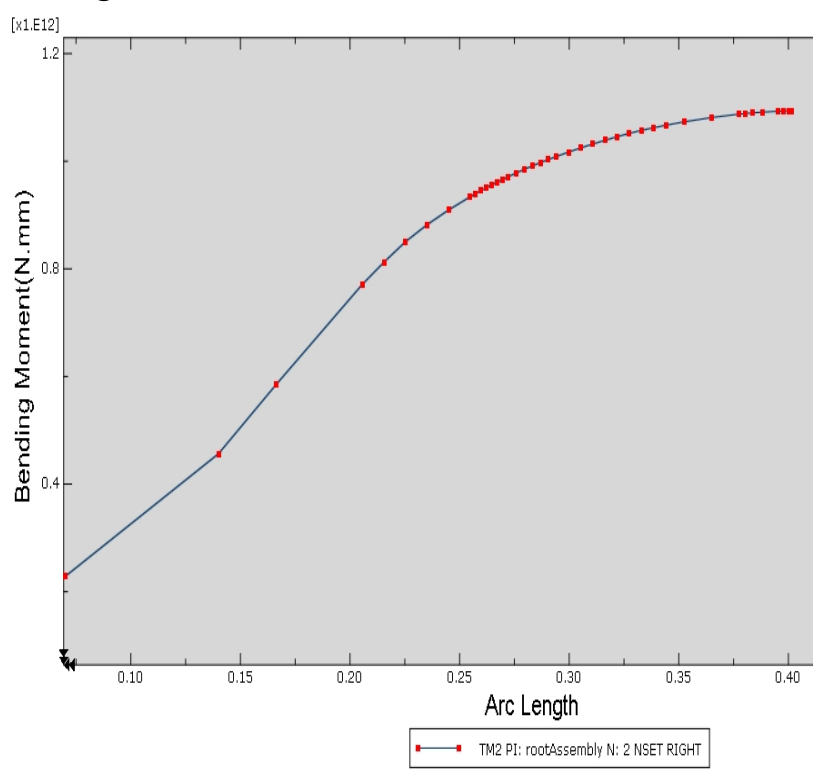

Fig. 9 ultimate bending moment - arc length

Through comparison we find that different length cabins have different result of ultimate bending moment. Through the analysis we can obtain that when the length of the cabin is small, the damage of model under the bending moment is mainly brittle fracture; when the length of the cabin is long, the damage of model under loading is mainly buckling instability destruction. However, buckling instability destruction form is the form of actual hull damage. Therefore, when we analyze the ultimate strength of the hull model, we should be appropriate to increase the core cabin of the model ${ }^{[8]}$, and avoid appearing brittle fracture failure mode.

\section{The influence of initial arc length increment on ultimate strength}

In order to reduce the time of the numerical simulation, taking the size of 0.4 cabins, through the displacement loading method calculation, finding different sizes of initial arc length increment have different numerical results of ultimate bending moment. The numerical result is shown in Fig.10.

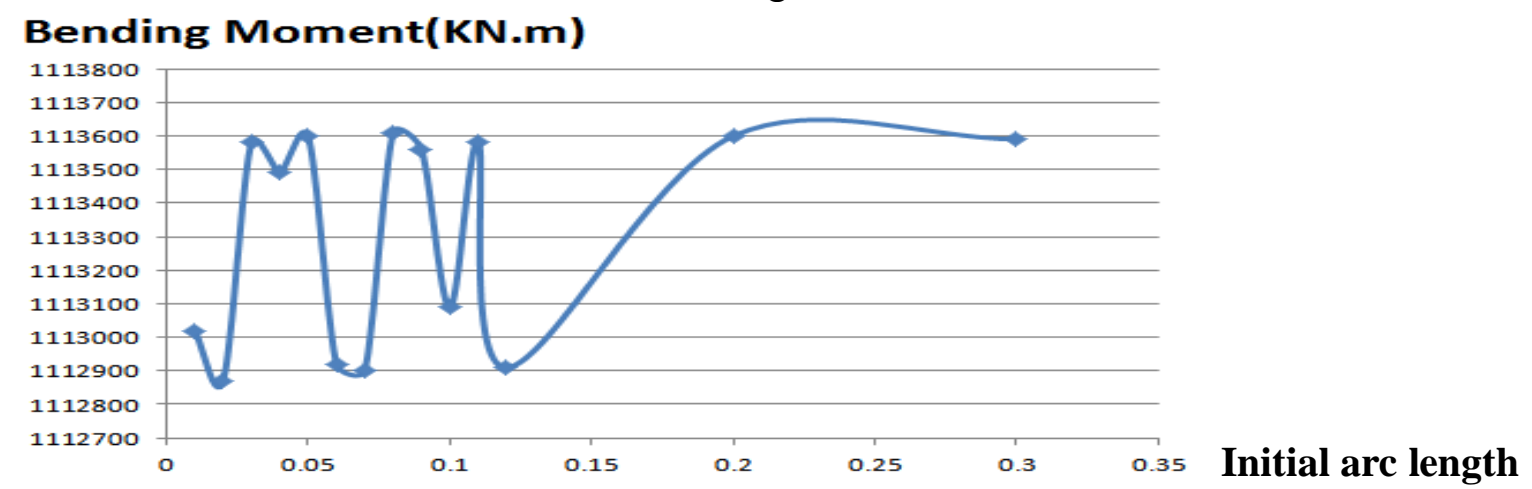

Fig.10 different sizes of initial arc length increment corresponding to different ultimate bending moment 
Through the table data, the ultimate bending moment calculated by changing different arc length increment has different values which the difference ranges of result are about $740 \mathrm{KN} \cdot \mathrm{m}$. We suggest using different arc length to calculate the ultimate bending moment, and then calculating the average value of ultimate bending moment. But when we are calculating the model by the software of ABAQUS, the arc length increment cannot be too small, also cannot be too much ${ }^{[6]}$. The reasons are that if the arc length increment is too much it is difficult to tracking changes of the real structure; if the arc length increment is too small, although it has less effect on the ultimate strength, we will spend more time to calculate model.

\section{The influence of mesh dimension on the ultimate strength}

Element meshing quality will directly affect the accuracy of results of ultimate strength, and at the same time also affect the computational time of the finite element model. In general, of course, the mesh more close, the result is more likely to be close to the real value. But the time needed for calculation also will increase significantly ${ }^{[3,6]}$. So, this experiment recommends that the distance of a rib is divided into two grids ${ }^{[1,8]}$.

\section{The impact of the material's yield strength on the ultimate strength}

In order to reduce the time of the numerical simulation, this paper takes the size of 0.4 cabins and displacement loading method to calculate different material's yield strength impact on the ultimate strength of hull. The calculation result is shown in Fig. 11.

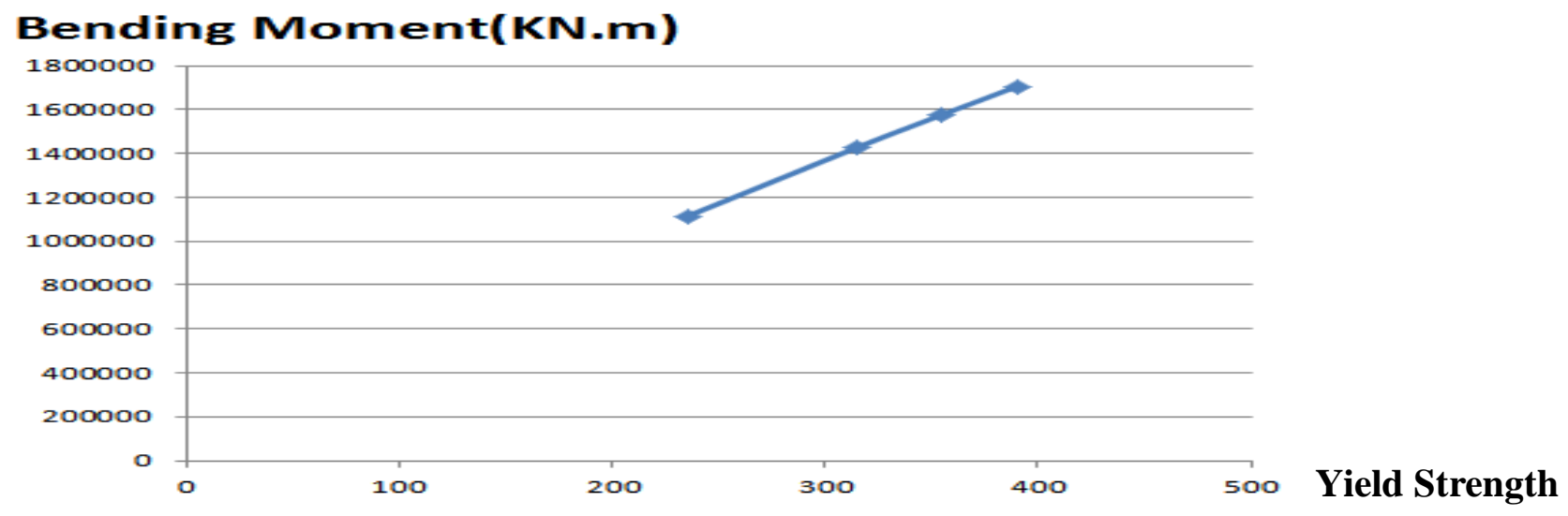

Fig. 11 the yield strength of material corresponding to the ultimate strength

As can be seen from the graph, ultimate bending moment and yield strength of the material have substantially linear relationship ${ }^{[6]}$. We can draw the conclusion that changing the material yield strength can improve the ultimate strength of the ship without sacrificing the hull weight.

\section{Conclusions}

This paper mainly introduces the principle of using nonlinear finite element method (fem) and the large-scale finite element software to do numerical simulation of river-to-sea transport container ship , and further to measure the ultimate bearing capacity of the ship by the value of ultimate bending moment.

Firstly, the paper uses the finite element software of MSC / PATRAN to build model. Secondly, we import the model into the software of ABAQUS and use the displacement method to calculate the ultimate bending moment ${ }^{[4,8]}$. In order to improve the accuracy of numerical simulation and the ultimate strength of hull, we need to pay attention to in the following aspects.

When we are doing the finite element numerical simulation analysis, We should pay attention to sparse degree and regular shape of element mesh, loading method, the length of cabin, initial arc length of step size and material yield strength so as to further improve the calculation accuracy of ultimate strength. But the process is relatively complicated and costs quite a lot of time to establish a large finite element model.

(1)When selecting the load loading mode, this paper suggests selecting displacement method to calculate. 
(2)When dividing the mesh in the model, this paper suggests trying to use regular element whose quadrilateral element aspect ratio of not more than 3, and triangle element controlled in the between 30 to 150 degrees. Apart from, the paper recommends that the distance of a rib is divided into two grids.

(3)The paper suggests using different arc length to calculate the ultimate bending moment, and then calculate the average value of ultimate bending moment. The size of the arc length is controlled between 0.05 and 0.1 as far as possible, and it should not be too large.

(4)Different length cabins have different result of ultimate bending moment, we should be appropriate to increase the core cabin of the model, and avoid appearing brittle fracture failure for the length cabins of mode are too short.

(5)We can use high-strength steel to increase the yield strength of material without sacrificing the hull weight, and then improve the ultimate strength of hull.

\section{Acknowledgments}

We acknowledge the support of International S\&T Cooperation Program of China (Grant No.2012DFR80170), National Natural Science Foundational of China (Grant No.51279182) and Zhejiang provincial Natural Science Foundation of China (Grant No.LQ13E090002).

\section{References}

[1] He F Q Ultimate strength study of river-to-sea ships [D]. Wuhan University of Technology, 2013:1-4, 50-58

[2] Shi G J Ultimate strength analysis of container ship hull structures [D].Shanghai Jiao Tong University, 2011:1-10

[3] Liu M R Ultimate strength analysis of typical hull structure [D].Harbin Engineering University, 2012:1-4, 62-63

[4] Li C F, H L Ren, G Q Fen, B Q Bai Assessing the ultimate strength of hull girders under local and external [J].Journal of Harbin Engineering University,2010,31(01):27-28

[5] CCS Rules for the classification of steel ships[S]. China communications Press 2012:55

[6] He S Y The analysis of ultimate longitudinal strength of ship hull girders [D].Wuhan University of Technology, 2005:35-46

[7] Wang L,J H Huang, P Chen, Z Q Wan Comparative analysis of harmonized common structural rules based on ultimate strength of intact ships and residual strength in grounding condition [J].Journal of Ship Mechanics, 2015, 19(4):448

[8] Tang H X, X Y Wang, J H Liu, W G Wu Calculation and experimental research of structural ultimate strength of warships [J]. Ship \& Boat, 2014, 26(3):26-27

[9] Wang J Y\&S L Zhang Ultimate strength experimental research for longitudinal box girders module model [J].Shipbuilding of China, 2011, 52(2):47-48 